JGG 2020;68:168-173

doi: 10.36150/2499-6564-376

\title{
Sexual differences regarding Alzheimer's disease: a narrative review
}

\author{
Immacolata Ambrosino ${ }^{1}$, Marco Vacante ${ }^{2}$, Cecilia Politi ${ }^{3}$, \\ Elena Barbagelata ${ }^{4}$, Tiziana Ciarambino ${ }^{5}$ \\ ${ }^{1}$ Medical Doctor, ASL Bari, Italy; ${ }^{2}$ Department of Surgery, University of Catania, Italy; ${ }^{3}$ Department \\ of Internal Medicine, Hospital of F. Veneziale, ASREM, Italy; ${ }^{4}$ Department of Internal Medicine, \\ Hospital of Savona, Italy; ${ }^{5} \mathrm{Hospital}$ of Marcianise, ASL Caserta, Italy
}

Background. Actually, there are about 5.2 million people with Alzheimer's dementia (AD) in the USA, 3.3 million are women and 1.9 million are men.

Objective. We will find out the status on the Alzheimer disease in relation to the brain structure, diagnosis, symptoms and therapy by gender. Methods. We analyzed, in this narrative review, the literature between 1989-2019 published on the Pubmed about Alzheimer disease and gender. The keywords were: Alzheimer disease and sex differences.

Conclusions. Women over 80 years have a higher incidence of $A D$ than men. Women have a faster age-related decline and are more likely to respond to donepezil and rivastigmina leading to less cognitive decline. At more advanced ages, women incurred greater costs than men of the same age. Woman gender could be a risk factor for evolution of AD. We will emphasize the importance of considering sex as a biological variable in the design of preclinical and clinical studies that investigate underlying pathologies or response to pharmacological interventions in AD.

Key words: Alzheimer disease, gender differences, dementia, women, gender related

\section{Correspondence}

Tiziana Ciarambino

PO Marcianise, ASL Caserta, via Orto dell'Abate, 81025 Marcianise (CE), Italy

Email: tiziana.ciarambino@gmail.com

\section{Conflict of interest}

The Authors declare no conflict of interest

How to cite this article: Ambrosino I, Vacante M, Politi C, et al. Sexual differences regarding Alzheimer's disease: a narrative review. Journal of Gerontology and Geriatrics 2020;68:168-73. https:// doi.org/10.36150/2499-6564-376

C Copyright by Società Italiana di Gerontologia e Geriatria (SIGG)

\section{(c) (1) (3) (}

\section{OPEN ACCESS}

This is an open access article distributed in accordance with the CC-BY-NC-ND (Creative Commons Attribution-NonCommercial-NoDerivatives 4.0 International) license. The article can be used by giving appropriate credit and mentioning the license, but only for non-commercial purposes and only in the original version. For further information: https://creativecommons.org/licenses/by-nc-nd/4.0/deed.en

\section{EPIDEMIOLOGY}

Alzheimer's disease (AD) is the most common type of dementia and comprises about $60-70 \%$ of all dementia cases ${ }^{1,3}$. Women are at the epicenter of the AD. In fact a woman's estimated lifetime risk for developing $A D$ is 1 in 6 and almost two-thirds of Americans with $A D$ are women ${ }^{4}$. Actually, there are about 5.2 million people with $A D$ in the USA. In particular, 3.3 million are women and 1.9 million are men ${ }^{5}$ (Fig. 1). Many European and Asian studies showed that the incidence of $A D$ increases with age and it is similar in men and women until 78-80 years. Up to age of 80 years, women have a higher incidence of $A D$ than men ${ }^{6-13}$. These differences across Europe, Asia and North America may be due to social, cultural and historical events ${ }^{14,15}$.

\section{SEX DIFFERENCES AND RISK FACTOR}

Sex differences in incidence of $A D$ are due to differences in brain structure between men and women. Head size and cerebral brain volume is 


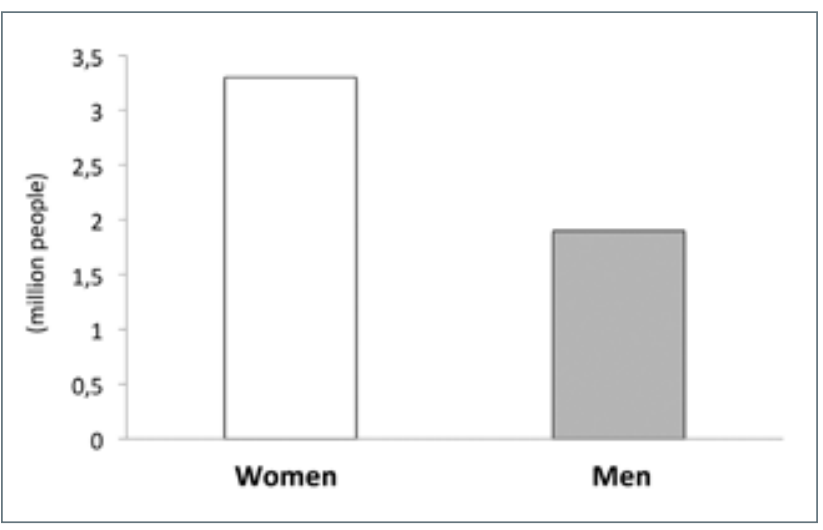

Figure 1. Prevalence in $A D$.

$10 \%$ larger in men than women ${ }^{16}$. Also, women have a higher percentage of grey matter and hippocampus, whereas men have a higher percentage of white matter, amygdala and thalamus ${ }^{17}$ (Fig. 2). These sex differences contribute to performance differences. In particular, men perform better on visually oriented tasks, while women perform better on verbal memory.

\section{¿4 allele of the Apo lipoprotein E (APO E) gene}

The $\varepsilon 4$ allele of the Apo lipoprotein E (APO E) gene is the best-known risk factor for $A D{ }^{18-21}$. The effect of the $\varepsilon 4$ genotype is more pronounced in women than in men ${ }^{22-23}$. In fact, an autopsy study found that amyloid plaque and neurofibrillary tangle pathology was greatest among women who were \&4 carriers. However, the risk of $A D$ is higher in women with homozygous $\varepsilon 4$ carriers compared with men with homozygous $\varepsilon 4$ carriers. Different studies reported that women with one \&4 allele had about four-fold risk of $A D$, whereas men with one $\varepsilon 4$ allele had a little increase risk ${ }^{24-26}$. Many studies reported the associations between ApoE and delusion, aggression, anxiety, apathy, and depression in $A D$. Noteworthy, the effect of ApoE $\varepsilon 4$ on $A D$ are more evident in women than in men ${ }^{27}$. A study pointed out that ApoE $\varepsilon 4$ status regulated the effects of sex hormones on neuropsychiatric symptoms of $A D$ in women patients but not in men ${ }^{25}$.

\section{HoRMONE REPLACEMENT THERAPY (HRT) AND AD}

Observational studies showed that the use of hormone replacement therapy (HRT) reduces the risk of $A D$ when it is initiated around the time of menopause ${ }^{28-34}$. Women who initiated HRT within 5 years of menopause had a $30 \%$ lower risk of AD compared to women who did not use HRT.

\section{EXERCISES AND AD}

Some studies suggest that exercise lowers the risk of AD more in women than men ${ }^{35,36}$. In particular, physical activity in the teenager was associated with the greatest reduction in risk of $A D{ }^{37}$.

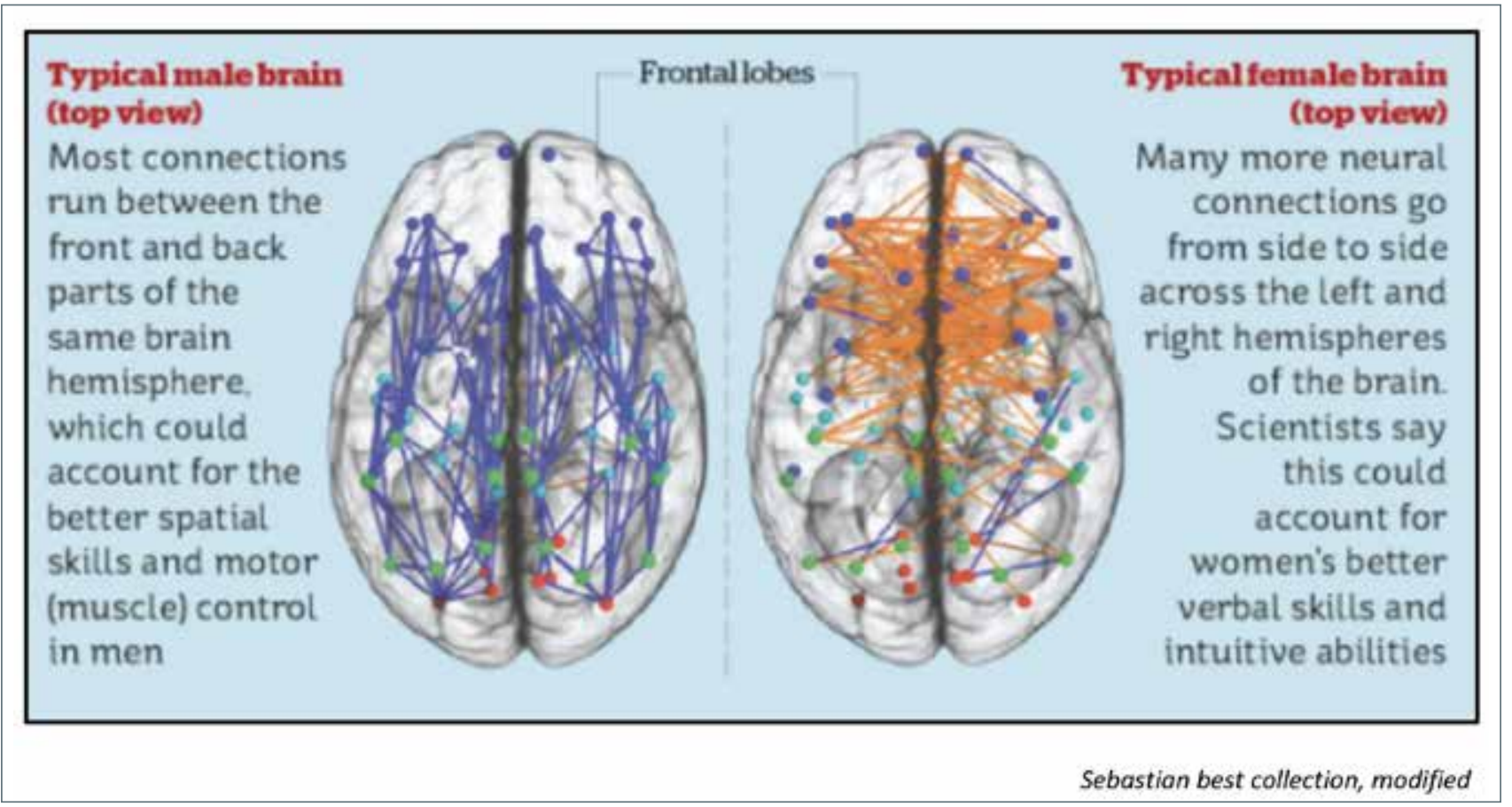

Figure 2. Difference by gender in brain structure. 


\section{SEX DIFFERENCES IN SYMPTOMS}

Several studies underlined that women show more evident language, semantic and orientation deficits, but methodological limitations might be responsible for this finding. Also, there is uncertainty on the validity of results reporting a more rapid cognitive decline in women. Women show a wider spectrum of dementia-related behavioral symptoms such as depression, while aggression is more frequent in men. Women seem to be more susceptible for pathological lesions while men have greater cognitive reserve ${ }^{38}$. Neuropsychiatric symptoms affect most of patients with $\mathrm{AD}$. Some authors suggested that patients with $A D$ were more frequently to show apathy and anxiety, while delusion was more common in female ${ }^{39-40}$. It was reported that the atrophy of hippocampal region was associated with agitation and aggression in $A D^{41}$. Interestingly, some studies demonstrated that women with Mild Cognitive Impairment $(\mathrm{MCl})$ and $A D$ and ApoE $\varepsilon 4$ carrier, had smaller hippocampal volumes than men ${ }^{42-44}$. However, it has been reported that premorbid depressive symptoms, significantly increased risk for dementia, particularly $A D$ in men but not in women ${ }^{45}$. However, the underlying pathophysiological mechanisms of neuropsychiatric symptoms of $A D$ are still not completely clear.

\section{SEX DIFFERENCES IN DIAGNOSIS}

Dementia diagnosis differs in men and women and depends on age and severity of the disease ${ }^{46}$. Older age is a risk factor in specific subgroups and it is associated with greater declines in global cognition ${ }^{47}$. In particular, Cherbuin et al. reported an association between mean arterial blood pressure and regional gray matter, both in men and women. Other authors reported an association between diastolic blood pressure and regional gray matter in men only ${ }^{48}$. Women have a higher risk of developing $A D$ than age-matched men, and showed faster age-related decline and greater deterioration of cognition compared to elderly male. However, a significant interaction by gender was found in patients with subjective memory complaints (SMC). Peres et al. showed that Instrumental Activities of Daily Living (IADL)-restriction increases the risk of dementia in men. The authors reported that, in men, IADL-restriction is only associated with increased risk of dementia at short-term, but not at longer term. In women, SMC is significantly associated with greater risk of dementia even at longer term ${ }^{47}$. Another study demonstrated sex differences in cognitive impairments. In particular, cognitive impairment in women is associated with greater declines in fluency capacity, while in men it is associated with significant declines in visual-spatial ability. In relation to the Mini Mental State Examination (MMSE) score, at initial diagnosis, it has been reported that it dropped significantly with increasing age. Gender and place of residence are significantly related to the MMSE score. In particular, it has been reported that women and institutionalized patients have lower MMSE scores under the age of 90 years and at all educational levels ${ }^{49-51}$. In women, delirium severity was related to dementia severity. For men, unlike for women, delirium severity was greater in those with less educational level ${ }^{52}$. Differences were reported in relation to gender and race. African American women reported greater difficulty with all Basic activities of Daily Living (BADLs) and IADLs with the exception of dressing and using the telephone. In comparison to men, non-Hispanic White women, also reported significantly increased difficulty with transfers, revealing a sex disparity in this mobility-related daily activity. African American men and non-Hispanic White men demonstrated an equivalent prevalence of difficulty for all BADL tasks. However, for all IADLs African American men reported greater difficulty compared to non-Hispanic White men ${ }^{53}$.

\section{SEX DIFFERENCES IN THERAPY}

Gender differences in symptom profile, living conditions, coping style and response might affect the outcome of psychosocial interventions (PSIs). Caregiver interventions found gender differences in PSls outcome. Women improved significantly with psychosocial interventions in relation to behavioral and psychological problems (Neuropsychiatric Inventory scores) at the 12-month. In studies investigating music therapy, to be male is, a predictor of poorer outcome in terms of greater physical aggression ${ }^{54}$. Furthermore, gender may influence the response to acetyl cholinesterase inhibitors (AChEls). Indeed, women are more likely to respond to donepezil and rivastigmina leading to less cognitive decline. However, sedative-hypnotics are over-prescribed to women. To this regard, women are at a greater risk for side effects ${ }^{55}$. In particular, it has been reported that bradycardia, from cholinesterase inhibitors, may affect more women, while men will experience more emergency hospitalizations and death after prescription of an antipsychotic. A study reported that gender differences in neuropsychiatric symptoms could influence the decision of treatment, and male patients could be more likely to receive antipsychotic medications ${ }^{55,56}$. 


\section{DEMENTIA AND HEALTH POLICY}

Differences are observed in relation to costs of dementia. In particular, it has been observed that about twothirds of the additional expenditure for dementia patients occurred in the long-term care. Long-term care spending increases in older age. In particular, women accounted for significantly lower health and significantly higher long-term care expenditures. Thus, at more advanced ages, women incurred greater costs than men of the same age ${ }^{57}$. These data represented a clear gender difference in the length of stay. The length of stay of women is longer than that of men. In particular, older age is predictor of the length of stay in women ${ }^{58}$.

\section{KEY MESSAGE}

- Many European and Asian studies showed that the incidence of $A D$ increases with age and it is similar in men and women until 78-80 years.

- Dementia diagnosis differs in men and women and depends on age and severity of the disease.

- Women have a higher risk of developing $A D$ than age-matched men, and showed faster age-related decline and greater deterioration of cognition than elderly male.

- Furthermore, gender may influence the response to acetyl cholinesterase inhibitors (AChEls). Indeed, women are more likely to respond to donepezil and rivastigmina leading to less cognitive decline.

- Women accounted for significantly lower health and significantly higher long-term care expenditures.

- In comparison to men, women reported significantly increased difficulty with transfers and in the mobility-related daily activity. However, several studies showed that high blood pressure, poor hearing, regular exercise, normal weight and having limitations in instrumental activities of daily living, were significant predictors of cognitive impairment in women.

\section{CONCLUSIONS}

Several mechanisms have been proposed to explain gender and educational differences in dementia risk. It suggests that inborn intelligence and a mentally stimulating lifestyle, such as educational and occupational attainments, may delays cognitive decline or dementia onset by increasing an individual's brain reserve ${ }^{59}$. In conclusion, gender could be a risk factor for evolution of AD. Future clinical trials should investigate the possible mediation effects of various biological factors (e.g. genetics, hormones, brain networks) in relation to the observed association and more studies need to assess gender differences rather than just adjusting for gender in analyses. Given the double aging of our society and the worldwide increase in sedentary lifestyle behavior, policy makers, insurance companies, and public health campaigns should place more emphasis on brainhealthy lifestyle changes in middle aged and younger subjects to promote optimal brain ageing and prevention of dementia in the long-term.

\section{References}

1 Reitz C, Brayne C, Mayeux R. Epidemiology of Alzheimer disease. Nat Rev Neurol 2011;7:137-52. https://doi. org/10.1038/nrneurol.2011.2

2 Mielke MM, Vemuri P, Rocca WA. Clinical epidemiology of Alzheimer's disease: assessing sex and gender differences. Clinical Epidemiology 2014;6:37-48. https://doi. org/10.2147/CLEP.S37929

3 Cacciatore F, Abete P, de Santis D, et al. Mortality and blood pressure in elderly people with and without cognitive impairment. Gerontology 2005;51:53-61. https://doi. org/10.1159/000081436

4 Hebert LE, Weuve J, Scherr PA, et al. Alzheimer disease in the United States (2010-2050) estimated using the 2010 census. Neurology 2013;80:1778-83. https://doi. org/10.1212/WNL.0b013e31828726f5

5 Association Alzheimer's. Alzheimer's disease facts and figures. Alzheimers Dement 2016;12:459-509. https://doi. org/10.1016/j.jalz.2016.03.001

6 Miech RA, Breitner JC, Zandi PP, et al. Incidence of AD may decline in the early 90s for men, later for women: the Cache County study. Neurology 2002;58:209-18. https:// doi.org/10.1212/wnl.58.2.209

7 Fratiglioni L, Viitanen M, von Strauss E, et al. Very old women at highest risk of dementia and Alzheimer's disease: incidence data from the Kungsholmen Project, Stockholm. Neurology 1997;48:132-8. https://doi.org/10.1212/ wnl.48.1.132

8 Ott A, Breteler MM, van Harskamp F, et al. Incidence and risk of dementia. The Rotterdam study. Am J Epidemiol 1998;147:574-80. https://doi.org/10.1093/oxfordjournals. aje.a009489

9 Letenneur L, Gilleron V, Commenges D, et al. Are sex and educational level independent predictors of dementia and Alzheimer's disease? Incidence data from the PAQUID project. J Neurol Neurosurg Psychiatry 1999;66:177-83. https://doi.org/10.1136/jnnp.66.2.177

10 Andersen K, Launer LJ, Dewey ME, et al. Gender differences in the incidence of $A D$ and vascular dementia: the EURODEM studies. EURODEM Incidence Research Group. Neurology 1999;53:1992-1997. https://doi.org/10.1212/wnl.53.9.1992

11 Ruitenberg A, Ott A, van Swieten JC, et al. Incidence of dementia: does gender make a difference? Neurobiol Aging 2001;22:575-80. https://doi.org/10.1016/s01974580(01)00231-7 
12 Yoshitake T, Kiyohara Y, Kato I, et al. Incidence and risk factors of vascular dementia and Alzheimer's disease in a defined elderly Japanese population: the Hisayama study. Neurology 1995;45:1161-8. https://doi.org/10.1212/ wnl.45.6.1161

13 Liu CK, Lai CL, Tai CT, et al. Incidence and subtypes of dementia in southern Taiwan: impact of socio-demographic factors. Neurology 1998;50:1572-9. https://doi. org/10.1212/wnl.50.6.1572

14 Plassman BL, Langa KM, Fisher GG, et al. Prevalence of dementia in the United States: the aging, demographics, and memory study. Neuroepidemiology 2007;29:125-32. https://doi.org/10.1159/000109998

15 Edland SD, Rocca WA, Petersen RC, et al. Dementia and Alzheimer disease incidence rates do not vary by sex in Rochester, Minn. Arch Neurol 2002;59:1589-93. https:// doi.org/10.1001/archneur.59.10.1589

16 Giedd JN, Raznahan A, Mills KL, et al. Review: magnetic resonance imaging of male/female differences in human adolescent brain anatomy. Biol Sex Differ 2012;3:19. https://doi.org/10.1186/2042-6410-3-19

17 Cosgrove KP, Mazure CM, Staley JK. Evolving knowledge of sex differences in brain structure, function, and chemistry. Biol Psychiatry 2007;62:847-55. https://doi. org/10.1016/j.biopsych.2007.03.001

18 Strittmatter WJ, Saunders AM, Schmechel D, et al. Apolipoprotein E: high-avidity binding to beta-amyloid and increased frequency of type 4 allele in late-onset familial Alzheimer disease. Proc Natl Acad Sci U S A 1993;90:197781. https://doi.org/10.1073/pnas.90.5.1977

19 Corder EH, Saunders AM, Strittmatter WJ, et al. Gene dose of apolipoprotein E type 4 allele and the risk of Alzheimer's disease in late onset families. Science 1993;261:921-3. https://doi.org/10.1126/science.8346443

20 Farrer LA, Cupples LA, Haines JL, et al. Effects of age, sex, and ethnicity on the association between apolipoprotein $\mathrm{E}$ genotype and Alzheimer disease. A meta-analysis. APOE and Alzheimer Disease Meta Analysis Consortium. JAMA 1997;278:1349-56. https://doi.org/10.1001/ jama.278.16.1349

21 Corder EH, Ghebremedhin E, Taylor MG, at al. The biphasic relationship between regional brain senile plaque and neurofibrillary tangle distributions: modification by age, sex, and APOE polymorphism. Ann N Y Acad Sci 2004;1019:24-8. https://doi.org/10.1196/annals.1297.005

22 Ungar L, Altmann A, Greicius MD. Apolipoprotein E, gender, and Alzheimer's disease: an overlooked, but potent and promising interaction. Brain Imaging Behav 2014;8:26273. https://doi.org/10.1007/s11682-013-9272-x

23 Corbi G, Conti V, Davinelli S, et al. Dietary phytochemicals in neuroimmunoaging: a new therapeutic possibility for humans? Front Pharmacol 2016;7:364 . https://doi. org/10.3389/fphar.2016.00364

24 Payami H, Zareparsi S, Montee KR, et al. Gender difference in apolipoprotein E-associated risk for familial Alzheimer disease: a possible clue to the higher incidence of Alzheimer disease in women. Am J Hum Genet 1996;58:803-11.
25 Fleisher A, Grundman M, Jack CR Jr, et al; Alzheimer's Disease Cooperative Study. Sex, apolipoprotein E epsiIon 4 status, and hippocampal volume in mild cognitive impairment. Arch Neurol 2005;62:953-7. https://doi. org/10.1001/archneur.62.6.953

26 Cristofano A, Sapere N, La Marca G, et al. Serum levels of acyl-carnitines along the continuum from normal to Alzheimer's Dementia. PLoS One 2016;11:e0155694. https:// doi.org/10.1371/journal.pone.0155694

27 Bretsky PM, Buckwalter JG, Seeman TE, et al. Evidence for an interaction between apolipoprotein $E$ genotype, gender, and Alzheimer disease. Alzheimer Dis Assoc Disord 1999;13:216-21. https://doi.org/10.1097/00002093199910000-00007

28 Morrison JH, Brinton RD, Schmidt PJ, et al. Estrogen, menopause, and the aging brain: how basic neuroscience can inform hormone therapy in women. J Neurosci 2006;26:10332-48. https://doi.org/10.1523/JNEUROSCl.3369-06.2006

29 Waring SC, Rocca WA, Petersen RC, et al. Postmenopausal estrogen replacement therapy and risk of AD: a population-based study. Neurology 1999;52:965-70. https://doi. org/10.1212/wnl.52.5.965

30 LeBlanc ES, Janowsky J, Chan BK, et al. Hormone replacement therapy and cognition: systematic review and meta-analysis. JAMA 2001;285:1489-99. https://doi. org/10.1001/jama.285.11.1489

31 Zandi PP, Carlson MC, Plassman BL, et al; Cache County Memory Study Investigators. Hormone replacement therapy and incidence of Alzheimer disease in older women: the Cache County study. JAMA 2002;288:2123-9. https://doi. org/10.1001/jama.288.17.2123

32 Henderson WW, Benke KS, Green RC, et al.; MIRAGE Study Group. Postmenopausal hormone therapy and Alzheimer's disease risk: interaction with age. J Neurol Neurosurg Psychiatry 2005;76:103-5. https://doi.org/10.1136/ jnnp.2003.024927

3з Whitmer RA, Quesenberry CP, Zhou J, et al. Timing of hormone therapy and dementia: the critical window theory revisited. Ann Neurol 2011;69:163-9. https://doi. org/10.1002/ana.22239

34 Shao H, Breitner JC, Whitmer RA, et al.; Cache County Investigators. Hormone therapy and Alzheimer disease dementia: new findings from the Cache County study. Neurology 2012;79:1846-52. https://doi.org/10.1212/ WNL.0b013e318271f823

35 Hogervorst E, Clifford A, Stock J, et al. Exercise to prevent cognitive decline and Alzheimer's disease: for whom, when, what, and (most importantly) how much? J Alzheimers Dis Park 2012;2:e117. https://doi.org/10.4172/21610460.1000e117

36 Clifford A, Bandelow S, Hogervorst E. The effects of physical exercise on cognitive function in the elderly: a review. In: Gariépy Q, Ménard R, Eds. Handbook of cognitive aging: causes, processes and effects. New York: Nova Science Publishers 2010, pp. 109-50.

37 Middleton LE, Barnes DE, Lui LY, et al. Physical activity over 
the life course and its association with cognitive performance and impairment in old age. J Am Geriatr Soc 2010;58:13226. https://doi.org/10.1111/j.1532-5415.2010.02903.x

38 Schmidt R, Kienbacher E, Benke T, et al. Sex differences in Alzheimer's disease. Neuropsychiatr 2008;22:1-15.

39 Ikeda M, Shigenobu K, Fukuhara R, et al. Delusions of Japanese patients with Alzheimer's disease. Int J Geriatr Psychiatry 2003;18:527-32. https://doi.org/10.1002/ gps. 864

40 Ott BR, Tate CA, Gordon NM, et al. Gender differences in the behavioral manifestations of Alzheimer's disease. J Am Geriatr Soc 1996;44:583-7. https://doi. org/10.1111/j.1532-5415.1996.tb01447.x

${ }^{41}$ Ropacki SA, Jeste DV. Epidemiology of and risk factors for psychosis of Alzheimer's disease: a review of 55 studies published from 1990 to 2003. Am J Psychiatry 2005;162:2022-30. https://doi.org/10.1176/appi. ajp.162.11.2022

42 Zuidema SU, de Jonghe JF, Verhey FR, et al. Predictors of neuropsychiatric symptoms in nursing home patients: influence of gender and dementia severity. Int J Geriatr Psychiatry 2009;24:1079-86. https://doi.org/10.1002/ gps.2225

${ }^{43}$ Henderson VW, Buckwalter JG. Cognitive deficits of men and women with Alzheimer's disease. Neurology 1994;44:90-6. https://doi.org/10.1212/wnl.44.1.90

44 Ott BR, Lapane KL, Gambassi G. Gender differences in the treatment of behavior problems in Alzheimer's disease. SAGE Study Group. Systemic Assessment of Geriatric drug use via Epidemiology. Neurology 2000;54:427-32. https://doi.org/10.1212/wnl.54.2.427

${ }^{45} \mathrm{Li} \mathrm{R}$, and van Singh M. Sex differences in cognitive impairment and Alzheimer's disease. Front Neuroendocrinol 2014;35:385-403. https://doi.org/10.1016/j. yfrne.2014.01.002

46 Teri L, Borson S, Kiyak HA, et al. Behavioral disturbance, cognitive dysfunction, and functional skill. Prevalence and relationship in Alzheimer's disease. J Am Geriatr Soc 1989;37:109-16. https://doi. org/10.1111/j.1532-5415.1989.tb05868.x

47 Peres K, Helmer C, Hamieva H, et al. Gender differences in the prodromal signs of dementia: memory complaint and IADL-restriction. A prospective population based cohort. J Alzheimers Dis 2011;27:39-47. https://doi.org/10.3233/ JAD-2011-110428

${ }_{48}$ Cherbuin N, Mortby ME, Janke AL, et al. Blood pressure, brain structure, and cognition: opposite associations in men and women Am J Hypertens 2015;28:225-31. https://doi.org/10.1093/ajh/hpu120

49 Pradier C, Sakarovitch C, Le Duff F, et al. The mini mental state examination at the time of Alzheimer's disease and related disorders diagnosis,according to age, education, gender and place of residence: a cross-sectional study among the French National Alzheimer database. PLoS One 2014;9:e103630. https://doi.org/10.1371/journal. pone. 0103630

50 Bianchetti A, Ferrara N, Padovani A, et al. Timely. Detection of mild cognitive impairment in Italy: an expert opinion. J Alzheimers Dis 2019;68:1401-14. https://doi. org/10.3233/JAD-181253

51 Limongi $F$, Noale $M$, Bianchetti $A$, et al.; $M C l$ Working Group. The instruments used by the Italian centres for cognitive disorders and dementia to diagnose mild cognitive impairment (MCl). Aging Clin Exp Res 2019;31:101-7. https://doi.org/10.1007/s40520-018-1032-8

52 Kolanowski AM, Hill NL, Kurum E, et al. Gender differences in factors associated with delirium severity in older adults with dementia. Arch Psychiatr Nurs 2014;28:187-92.

${ }_{53}$ Garrett SL, Sawyer P, Kennedy RE. Racial and sex differences in associations between activities of daily living and cognition among community-dwelling older adults. J Am Geriatr Soc 2013;61:2174-80.

54 Baron S, Ulstein I, Werheid K. Psychosocial interventions in Alzheimer's disease and amnestic mild cognitive impairment: evidence for gender bias in clinical trials. Aging Ment Health 2015;19:290-305.

55 Corbi G, Gambassi G, Pagano G, et al. Impact of an innovative educational strategy on medication appropriate use and length of stay in elderly patients. Medicine (Baltimore) 2015;94:e918. https://doi.org/10.1097/ MD.0000000000000918

56 Caruana-Pulpan O, Scerri C. Practices in diagnosis, disclosure and pharmacotherapeutic management of dementia by general practitioners - a national survey. Aging Ment Health 2014;18:179-86.

57 Schwarzkopf L, Menn P, Leidl R, et al. Excess costs of dementia disorders and the role of age and gender - an analysis of German health and long-term care insurance claims data.BMC Health Serv Res 2012;12:165.

58 Ono T, Tamai A, Takeuchi D, et al. Predictors of lenght of stay in a ward for demented elderly: gender differences. Psychogeriatrics 2010;10:153-9.

59 Belleville S, Moussard A, Ansaldo Al, et al. Rationale and protocol of the ENGAGE study. A double blind randomized controlled preference trial using a comprehensive cohort design to measure the effect of a cognitive and leisure based intervention in older adults with a memory complaints. Trials 2019. https://doi.org/10.1186/s13063-0193250-6 